\title{
New Supported lonic Liquid as Catalyst for arylation of diorgano diselenides with arylboronic acids
}

\author{
Rodrigo Giovenardi (PG), Daniel S. Rampon (PG), Dagoberto Oliveira Silva (PG), \\ Tiago L. Silva (PG), Raoní S. Rambo (PG), Jairton Dupont (PQ) and Paulo H. \\ Schneider (PQ)*
}

Instituto de Química, UFRGS, Avenida Bento Gonçalves, 9500, Porto Alegre, RS, Brasil, 91501-970

*paulos@iq.ufrgs.br

Keywords: Ionic Liquids, Arylboronic Acids, Diorgano Diselenides, Aryl Selenides.

\section{INTRODUCTION}

Research on organoselenides has been driven by the potential applications of selenium compounds in modern organic synthesis and catalysis. ${ }^{1}$ Among these organoselenium compounds, aryl- and vinyl selenides are certainly the most applied compounds in organic synthesis. A large number of methodologies have been reported to prepare these compounds; however, the reaction often needs harsh reaction conditions or non-recyclable catalysts. ${ }^{2}$ In this context, the use of ionic liquids (IL) as recyclable solvent for mild preparation of diorganyl selenides was recently described. ${ }^{3}$ On the basis of economic criteria and possible toxicological concerns, it is desirable to minimize the amount of utilized ionic liquid and catalyst in a potential process. Thus, the concept of supported ionic liquid catalysis (SILC) ${ }^{4}$ emerges as alternative for green synthesis of organoselenium compounds. Therefore, herein we disclose a new and efficient methodology to prepare diorganyl selenides employing the SILC system with In (III) lewis acid as anion (Scheme 1).

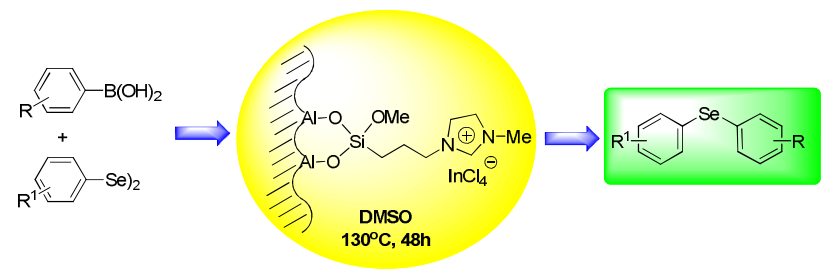

Figure 1. Application of $\mathrm{Al}_{2} \mathrm{O}_{3}-[\mathrm{MPIM}]\left[\mathrm{InCl}_{4}\right]$ alkoxysilane derivatives for arylation of diorgano diselenides.

\section{RESULTS AND DISCUSSION}

The support and characterization of new [MPIM] $\left[\mathrm{InCl}_{4}\right]$ alkoxysilane derivative on $\mathrm{Al}_{2} \mathrm{O}_{3}$ was achieved as previous described. ${ }^{5}$ Our initial studies have focused on the development of an optimum set of reaction conditions. In this approach, diphenyl diselenide 1 and 4-methoxyphenyl boronic acid 2 were used as model substrates (Table 1).
Table 1. Optimization of reaction conditions.

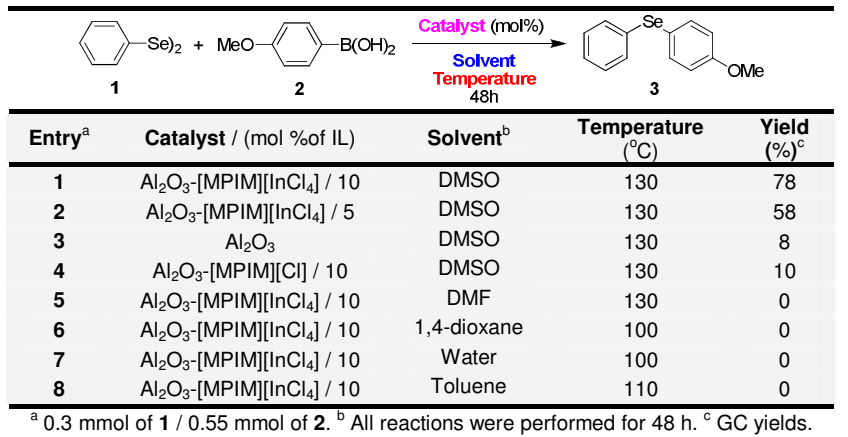

The use of catalyst in an amount of $10 \mathrm{~mol} \%$ on DMSO at $130^{\circ} \mathrm{C}$ gives the best results, furnish the compound 3 in good yield (Table 1, entry 1 ). It can be observed lower yields with reduction of reaction times and temperatures. When the catalyst loading was reduced ( $5 \mathrm{~mol} \%$ ), the yield decreases to $58 \%$ (entry 2). The desired product was not obtained only which $\mathrm{Al}_{2} \mathrm{O}_{3}$ or in absence of In (III) as anion (entries 3 and 4). These results suggest that the success of the reaction depends of lewis acid in the supported ionic liquid. Finally, we observed that the solvent was important for the reaction success. When DMF, 1,4-dioxane, water or toluene were used, the desired product 3 was not obtained (entries 5-8).

\section{CONCLUSION}

In conclusion, we demonstrate a new and efficient methodology to prepare diorganyl selenides employing the SILC system. Studies towards the catalyst recyclability, mechanism and scope reaction are in progress.

\section{ACKNOWLEDGEMENTS}

CAPES, CNPq, INCT-Catalysis, FAPERGS and UFRGS.

\section{REFERENCES}

${ }^{1}$ Wirth, T. Angew. Chem. Int. Ed. 2009, 48, 8409.

2 Perin, G.; et al. Chem. Rev. 2009, 109, 1277.

${ }^{3}$ Braga, A. L. J. Org. Chem. 2010, 75, 3886.

${ }^{4}$ (a) Riisager, A.; et al. Topics in Catalysis. 2006, 40, 91. (b) Mehnert, C. P.

Chem. Eur. J. 2005, 11, 50.

${ }^{5}$ Wang, Q.; et al. Analyst. 2006, 131, 1000 